\title{
GROUND DEFORMATION MONITORING AT CONTINENTAL SCALE: THE EUROPEAN GROUND MOTION SERVICE
}

\author{
M. Crosetto ${ }^{1, *}$, L. Solari ${ }^{1,2}$, J. Balasis-Levinsen ${ }^{3}$, N. Casagli ${ }^{4}$, M. Frei ${ }^{5}$, A. Oyen ${ }^{6}$, D.A. Moldestad ${ }^{7}$ \\ ${ }^{1}$ Centre Tecnològic de Telecomunicacions de Catalunya (CTTC/CERCA), Geomatics Division, Av. Gauss, 7, \\ E-08860 Castelldefels (Barcelona), Spain, mcrosetto@cttc.cat, lsolari@cttc.cat \\ 2 European Environment Agency, Kongens Nytorv 6, 1050 Copenhagen (Denmark) \\ ${ }^{3}$ Agency for Data Supply and Efficiency, Rentemestervej 8, 2400 Copenhagen (Denmark) - jofle@sdfe.dk \\ ${ }^{4}$ University of Firenze, Department of Earth Sciences, Via La Pira 4, 50121 Firenze (Italy) - nicola.casagli@unifi.it \\ ${ }^{5}$ Bundesantalt für Geowissenschaften und Rohstoffe, Stilleweg 2, 30655 Hannover (Germany) - Michaela.Frei@bgr.de \\ ${ }^{6}$ Ministerie van Infrastructuur en Waterstaat, Rijnstraat 8, 2515 XP Den Haag (The Netherlands) - anneleen.oyen@rws.nl \\ ${ }^{7}$ Norsk Romsenter, Drammensveien 165, 0277 Oslo (Norway) - dag.anders.moldestad@spaceagency.no
}

KEY WORDS: SAR, Persistent Scatterer Interferometry, Copernicus, European Ground Motion Service

\section{ABSTRACT:}

The Persistent Scatterer Interferometry is a powerful technique for ground motion detection and monitoring over wide areas. In the recent years, PSI has undergone a rapid evolution, largely thanks to the launch of the Copernicus Sentinel-1 constellation, the refinement of algorithms, and the increased computational capabilities. These factors allow for using Sentinel-1 interferometric data to develop ground deformation services for wide-area monitoring. Firstly, we review examples of services for national or regional deformation monitoring. The paper then describes the European Ground Motion Service (EGMS), part of the Copernicus Land Monitoring Service. The EGMS represents a unique initiative for performing ground deformation monitoring on a European scale.

\section{INTRODUCTION}

Satellite-based remote sensing allows us to image wide areas, even at continental scale. This is a fundamental characteristic for monitoring different types of phenomena. In the field of ground deformation monitoring, several radar satellites (e.g. Sentinel-1, TerraSAR-X, etc.) provide observations at global level. The class of techniques that exploits of such observations is the so-called Persistent Scatterer Interferometry (PSI), which represents an advanced class of Differential SAR interferometry (DInSAR), see Crosetto et al. (2016) and Pepe and Calò (2017).

The DInSAR technique exploits the interferometric phase of at least two Synthetic Aperture Radar (SAR) images. Among others, the interferometric phase is related to the topography in the observed scene and to the ground displacements occurring between the two image acquisitions. The first component (topography) is usually removed using a Digital Elevation Model (DEM) of the observed scene. DInSAR is a rather straightforward technique, which has been successfully used in several fields, e.g. seismology (Peltzer and Rosen, 1995), volcanology (Massonnet and Sigmundsson, 2000; Antonielli et al. 2014), glaciology (Rignot et al., 1997), landslides (GarcíaDavalillo et al., 2014), ground subsidence and uplift (Amelung et al., 1999), etc. Several examples of DInSAR applications are reviewed in Massonnet and Feigl (1998) and Hanssen (2001).

Compared to classical DInSAR techniques, the PSI techniques have advanced capabilities for measuring and monitoring deformation. This is largely due to the exploitation of large sets of SAR images acquired over the same area of interest, and the use of advanced data processing, modelling and analysis tools to analyse the SAR image stacks. As described in the following section, the PSI technique has undergone a very important development in the last two decades, starting with the publication of the first PSI technique (Ferretti et al., 2000), and today allowing for the monitoring of wide areas with a high spatial resolution (e.g. Figure 1). This allows for focusing on the deformation of e.g. single buildings, structures, and infrastructure (Crosetto et al., 2010), see Fig. 2.

This paper briefly describes the key aspects of the PSI development in the last two decades, focusing on the PSI wide area monitoring capabilities, see Section 2. Then, Section 3 reviews some of the most important ongoing wide-area PSI initiatives. Finally, in Section 4 it describes an ongoing ambitious European initiative: the establishment of the Copernicus European Ground Motion Service.

\section{PERSISTEN SCATTERER INTERFEROMETRY}

The current capabilities of the PSI techniques are the result of intense research and development activities in the last twenty years. We briefly discuss three main factors that are key to enable the wide area PSI capability, namely the availability of SAR data coming from multiple spaceborne sensors; an improvement of the PSI data analysis capabilities; and the significant increase in the computational capabilities.

The first factor is SAR data availability. At the time of writing this paper, there are more than 15 active spaceborne SAR systems. They include sensors for acquiring imagery with medium and very high resolutions. The most important system is surely the European Commission's Copernicus Sentinel-1 constellation. This includes two sensors: $1 \mathrm{~A}$ and $1 \mathrm{~B}$ (sentinel. esa.int/web/sentinel/missions/sentinel-1). Sentinel-1 offers improved data acquisition performances. This regards the area coverage, revisiting time and data throughput. Since the launch of Sentinel-1A in 2014, all these aspects have contributed to improving the deformation monitoring potential of PSI. Sentinel-1, like the entire Copernicus Programme, is supported by an open-source distribution strategy (Torres et al., 2012).

\footnotetext{
* Corresponding author
} 


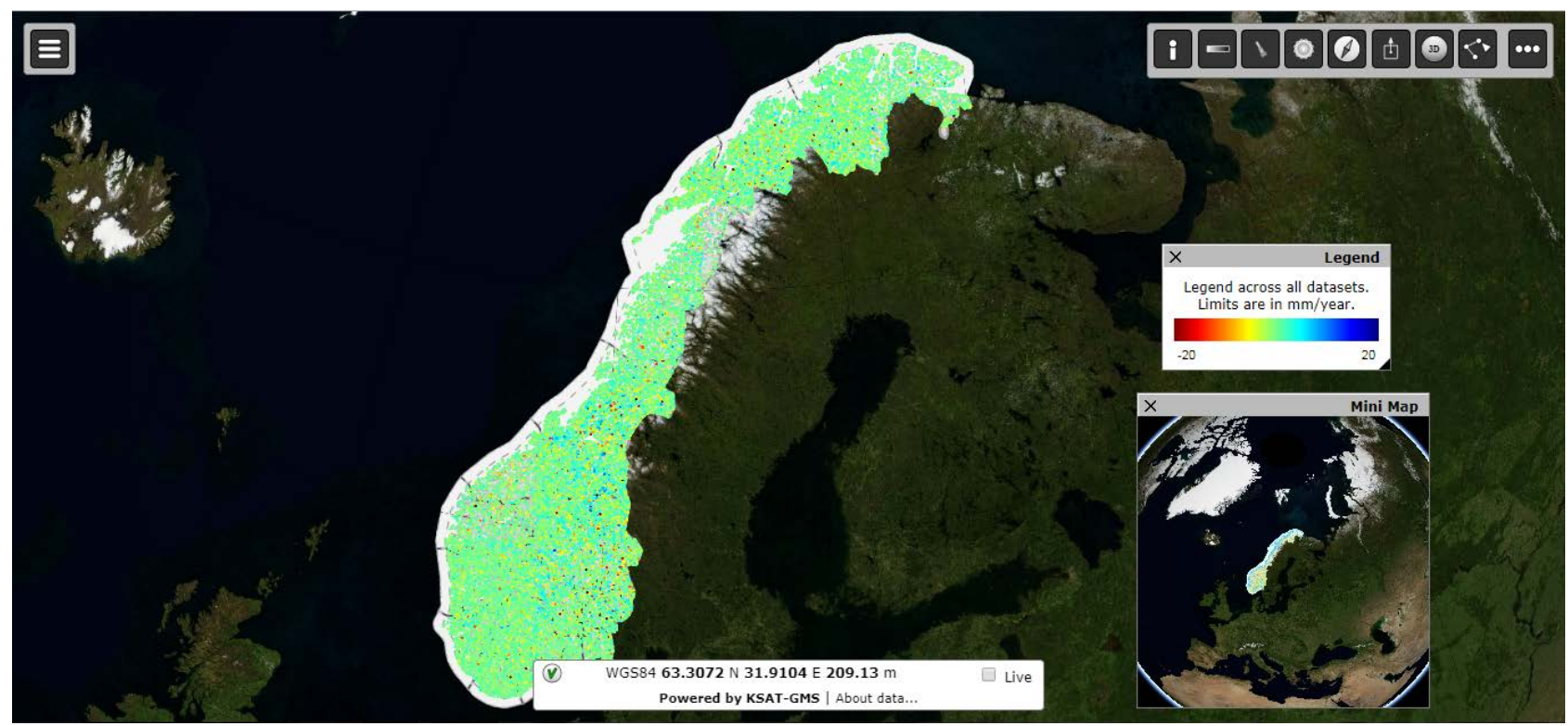

Figure 1. Example of wide area PSI monitoring: geoportal of the Norway Ground Motion Service - https://insar.ngu.no.

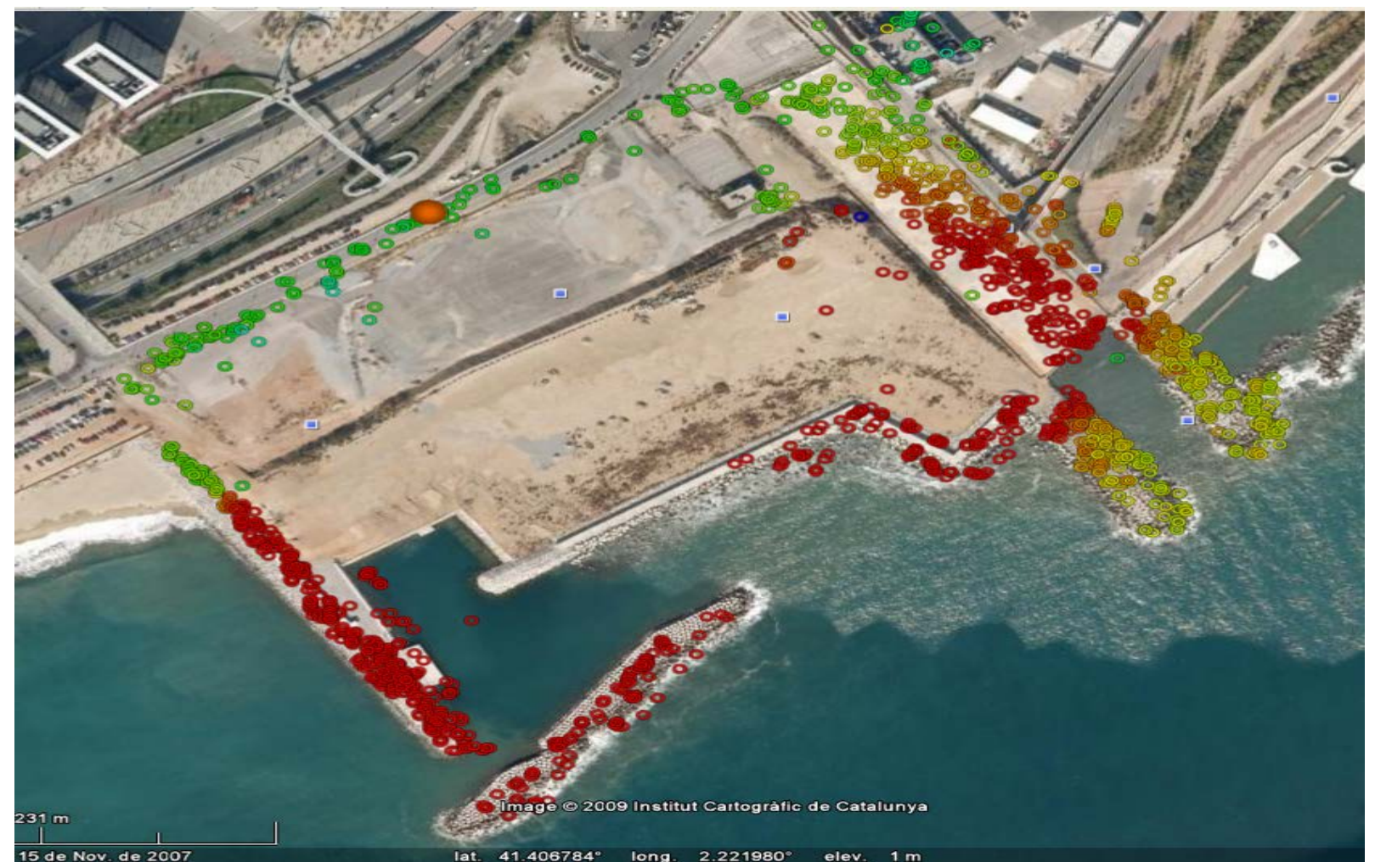

Figure 2. Example to show the high-resolution capability of PSI. This result was obtained using the PSI chain of CTTC and using very high-resolution SAR data from the TerraSAR-X sensor, covering the city of Barcelona (Spain).

The capabilities of PSI based on Sentinel-1 images has been documented in several papers. Just to mention some, see examples related to landslide monitoring (Barra et al., 2015; Béjar-Pizarro et al., 2017; Intrieri et al., 2018; Solari et al., 2020); subsidence monitoring (Sowter et al., 2016; Devanthéry et al., 2018; Du et al., 2018); and mining activity (Ng et al., 2017; Carlà et al., 2018).

In addition to the capability of existing SAR systems, it is worth mentioning that there are huge archives of SAR images that cover the last thirty years. The most important ones start in
1991, with the medium-resolution C-band data from the ERS-1 sensors. Thanks to such data archives, the PSI technique enables the studying of past deformation phenomena.

The second important factor is the development of advanced data processing and analysis techniques. Since the publication of the first PSI technique (Ferretti et al., 2000 and 2001), several different PSI approaches have been proposed. They cover different aspects of the data analysis, see for a review Crosetto et al. (2016). Of interest are the techniques that allow us to exploit two types of measurement points: the persistent 
scatterers and distributed scatterers, e.g. see Lanari et al., (2004) and Ferretti et al. (2011).

The third important factor is the available computation capability. Since the beginning of the SAR system era, the data acquisition capability of spaceborne sensors has always greatly exceeded the capacity for data processing and analysis. This is due to the large size of the SAR imagery and to the complexity and computational costs. The net result is that only a fraction of the acquired data has been exploited so far.

In the last years, different groups have worked to extend the PSI data processing. They have proposed to exploit advanced computational resources, such as cloud computing, distributed computing architectures, parallel computing, and so on. It is worth emphasising that the available computational resources have also notably improved in the last decade, and that their cost has drastically reduced. The result is that now PSI data analyses over wide areas, and using large stacks of images, is technically feasible. Examples are described in Zinno et al. (2015) and De Luca et al. (2017), etc.

\section{WIDE AREA DEFORMATION MONITORING}

This section briefly discusses the most important wide area deformation monitoring services that have been implemented or that are planned at European level.

There is an increasing interest of several European countries to monitor their territory with nation- or region-wide radar-based monitoring systems.

The first national-scale PSI service covered the entire territory of Italy. It was based on the first generation of C-band data from the ERS-1, ERS-2 and Envisat SAR sensors. In a later stage the very high-resolution imagery from COSMO-SkyMed were used. A description of the service is provided in Costantini et al., (2017).

Norway has launched in November 2018 its InSAR Norway Service, which is based on Sentinel-1 data. This is the first example of a nation-wide Ground Motion Service (GMS) that is freely distributed to the general public. The data can be accessed through a WebGIS (Web Geographic Information System) interface (available at https://insar.ngu.no). The WebGIS includes ascending and descending deformation maps and time series of deformation. The service consists of over 3.8 billion measurement points, with an average point density of 11000 point $/ \mathrm{km}^{2}$. The service is operated by the Geological Survey of Norway (NGU).

Germany launched its GMS at the end of November 2019. The service is called BodenBewegungsdienst Deutschland, BBD. It is managed by the German Geological Survey (BGR). A complete description of the service is provided in Kalia et al. $(2017,2020)$. The data are freely available at full resolution at the service portal, https://bodenbewegungsdienst.bgr.de, see Figure 3.

The service uses nationwide Persistent Scatterer Interferometry (PSI) data based on Sentinel-1 SAR data collected from the ascending and descending orbit. More than 200 continuous GNSS (Global Navigation Satellite System) stations are used to calibrate and validate the PSI datasets. The core data set comprises approximately 100 million measurement points for Germany, which are displayed against the background of a map of Germany using modern WebGIS technologies. Functions such as the visualization of the movement time series, dynamic queries and download expand the possible uses.

In Italy, three regions have already implemented a GMS focused on the early detection of abrupt motion changes. The services are based on Sentinel-1 imagery, using a 12-day image update (Raspini et al., 2018; Solari et al., 2019; Del Soldato et al., 2019). Other regions will follow in the near future, as planned in the Italian Space Economy Strategic Plan (Comerci and Vittori, 2019).

The Tuscany Region freely and continuously distributes updated interferometric products through an open WebGIS, where the user can visualize and download deformation maps and time series derived using both ascending and descending orbits, see Figure 4. The web platform contains guidelines that explain the technical background of the technique and give some tips for result interpretation. The service is available at www.regione.toscana.it/-/attivita-di-monitoraggio-del-rischioidrogeologico-del-territorio. The key interferometric products (the deformation maps and the anomalies maps) are integrated into an operational procedure to downscale data to different kind of users, e.g. municipalities and civil protection at regional and local scale. The deformation maps are used e.g. for landslide mapping and state of activity estimation.

In Denmark, the GMS is managed by the governmental Agency for Data Supply and Efficiency (SDFE). The project is in a preoperational stage where deformation products have been generated and made freely available for public and private endusers; a fully open WebGIS has, however, not yet been developed. The service is based on Sentinel-1 data.

The first deformation map contains over 7 million measurement points, with an average density of $160 \mathrm{PS} / \mathrm{km}^{2}$. The interferometric SAR data were analysed using the SqueeSAR algorithm (Ferretti et al., 2011), which selects both persistent scatterers and distributed scatterers to maximize the measurement density. Selected products in the GMS include deformation maps and time series for the satellite line-of-sight, east-west and vertical directions, respectively, as well as hotspots to highlight anomalous deformation patterns.

In the Netherlands the GMS is managed by the Ministry of Infrastructure and Water Management. The aim of the Dutch GMS is to provide a national base map for height change obtained through DInSAR. The service is based on Sentinel-1 imagery. It is planned that the Netherlands will launch its nationwide deformation service, titled "InSAR based ground motion service for the Dutch built environment" in the near future.

France is currently testing its GMS. However, it did not publish their data yet because they are under evaluation. Slovakia developed a prototype of GMS at regional scale, which, however, has not been published yet. Austria, Belgium, Great Britain, Poland and Portugal are currently developing the idea of a GMS.

Greece has a prototype of regional interferometric monitoring service and is discussing about a national GMS.

Cyprus ran a GMS in the past and will start an ESA PECS (Plan for European Cooperating State Charter) activity in 2020 with respect to "Direct observation and monitoring of instability via satellite radar interferometry". Ireland and Sweden are discussing the possibility of implementing a GMS. 


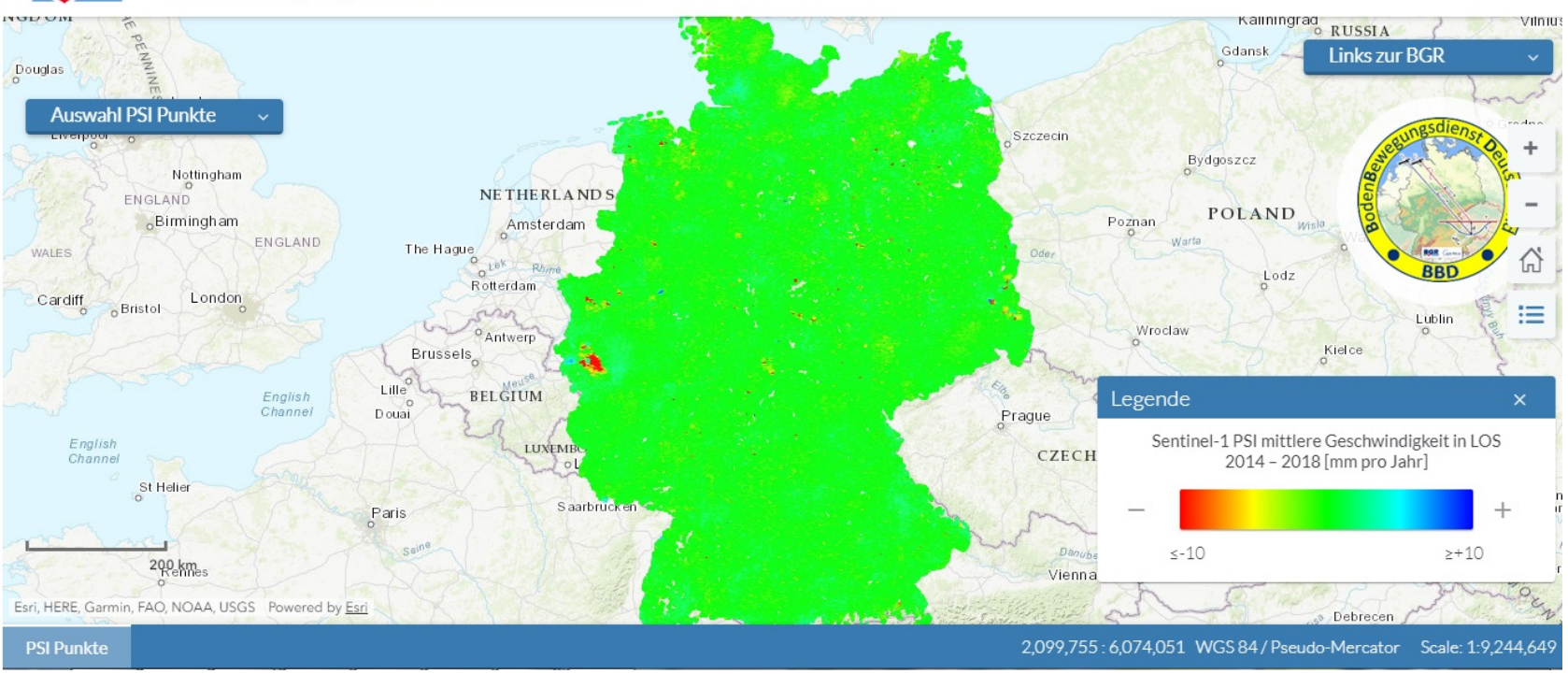

Figure 3: View of the geoportal of the BodenBewegungsdienst Deutschland. https://bodenbewegungsdienst.bgr.de.

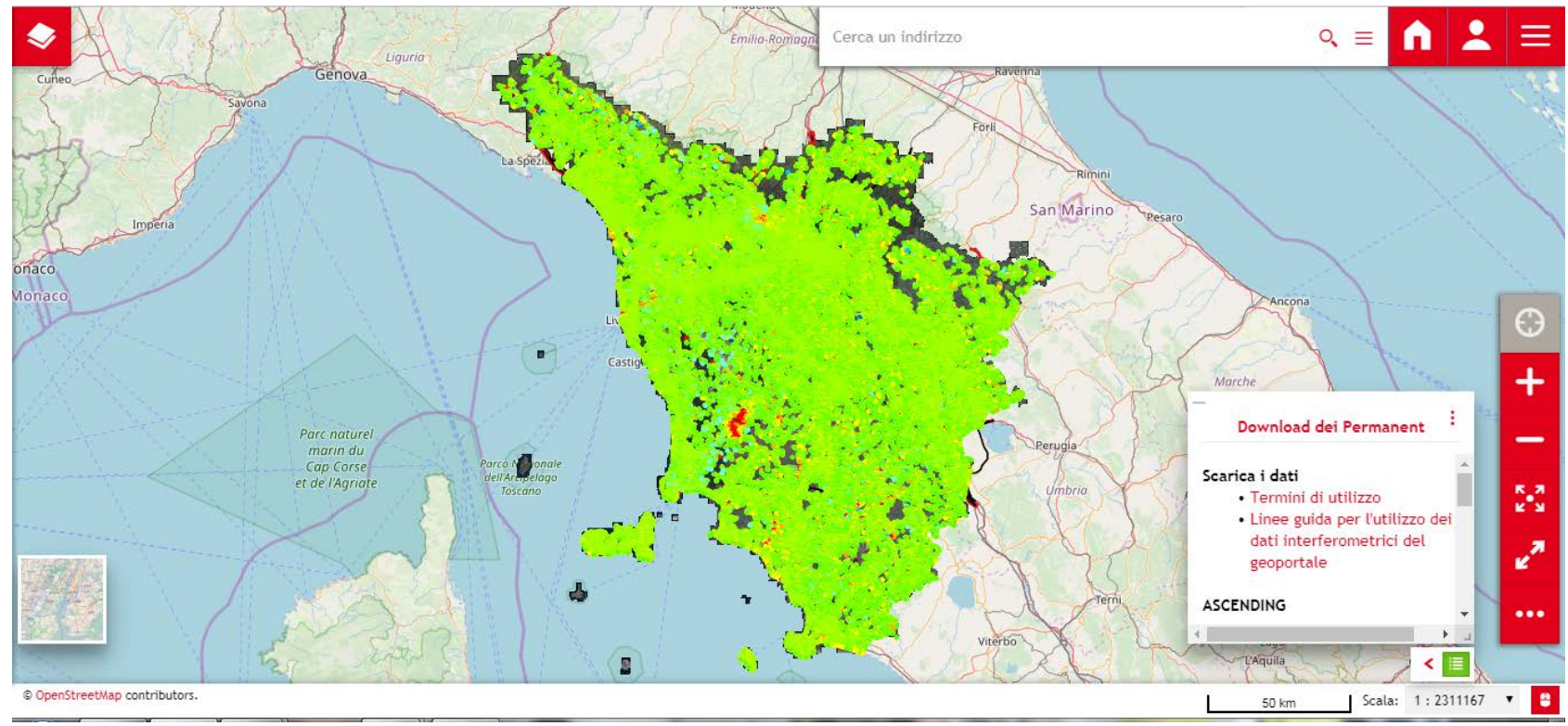

Figure 4: View of the geoportal of the Tuscany region related to the activity of monitoring of the hydrogeological risk. https://geoportale.lamma.rete.toscana.it/difesa_suolo/\#/viewer/openlayers/326.

\section{THE EUROPEAN GROUND MOTION SERVICE}

The above section clearly shows that on a European level, there is a high interest to implement GMS', both at national and regional levels. This is a very important effect of the Copernicus Sentinel-1 mission. In this section, we describe the panEuropean initiative, which will further extend the impact of such GMS'.

In 2017, the Copernicus User Forum and the Copernicus Committee approved the addition of the European Ground Motion Service (EGMS) to the Copernicus Land Monitoring Service's product portfolio (land.copernicus.eu). The EGMS is being implemented under the responsibility of the European Environment Agency (EEA, www.eea.europa.eu).
The basic characteristics of the service were defined by the socalled EGMS Task Force, which summarized them in the EGMS White Paper (EGMS Task Force, 2017). A specific working group was commissioned by EEA in 2019 to further define the technical specifications of the service. The Product Specification Document and the Service Implementation Plan for the EGMS are available online (Larsen et al., 2020).

The following section highlights some of the most important aspects of the EGMS.

The aim of the service is to provide consistent, updated, standardized, harmonized information regarding natural and 
anthropogenic ground motion phenomena over Europe. The service will be free and open.

The service will be based on Sentinel-1 imagery, which will be processed at full resolution, using an Advanced SAR Interferometry (A-DInSAR) approach. The service will use both ascending and descending images, acquired with a revisit time of six days.

As it is now, the EGMS will first include a baseline processing, which will use the archive imagery starting from 2014/2015. This will be followed by product updates every 12 months.

There will be three main EGMS products, which are briefly described below. The first product (Level 2a) will be based on the basic output of any PSI analysis: the geocoded deformation velocities and time series. These products will be provided in the line-of-sight of the radar imagery. They will be delivered separately for each used image frame.

The second product (Level 2b) will be of higher level. In order to derive it, the Level 2a product will be integrated with Global Navigation Satellite System (GNSS) data. The GNSS data will be used to estimate the spatial low deformation frequencies, while the A-DinSAR will be exploited to estimate the higher spatial frequencies. An important characteristic of this product is that it will be a unique seamless, mosaicked product. This will facilitate the end user interpretation and exploitation of the results.

In the third product (Level 3), a further improvement will be made. The aim of Level 3 will be to overcome the limitation of the line-of-sight deformation, which can be an obstacle for the exploitation and interpretation of the results. In this case, the Level $2 \mathrm{~b}$ product will be fused, in order to derive two different products: the vertical deformation and the horizontal deformation in the east-west direction. It is worth emphasizing that this product will be derived at a coarser spatial resolution than the other products.

An important priority of the EGMS will be to maximize its societal impact. This requires reaching as many end users as possible. In order to do so, the products will be free and open. The service will provide appropriate web-based tools to visualize, interact with the data and to analyze and exploit them. In parallel, protocols and best practice examples will be disseminated.

The quality of the EGMS products will be of great importance. The consortium in charge of the production will implement appropriate quality control and verification procedures. This is important for a challenging service such as the EGMS that will involve the processing of huge datasets.

In addition to this, validation will be performed at the end of each production cycle. A validation team, (created in the framework of an external contract), will advise and perform independent validation of the EGMS products, maintaining and evolving as necessary the quality standards, and maintaining a front-end information for users on the quality of the EGMS products.

In the context of Copernicus, emphasis will be given to user uptake and the development of new applications based on the EGMS products. A wide range of potential users and application will benefit from the EGMS products. To mention some of them:
- Public authorities at European, national, regional and municipal levels;

- Geological and geophysical surveys;

- Geodetic and topographic surveys;

- Civil Protection authorities;

- Mining industry;

- Oil and gas industry;

- Road and railway administrations;

- Water management authorities;

- Cultural heritage institutions;

- Regulators and planners;

- Engineering companies;

- Insurance industry;

- Research centers and universities;

- Citizens.

\section{ACKNOWLEDGEMENTS}

This work has been partially funded by the Spanish Ministry of Economy and Competitiveness through the DEMOS project "Deformation monitoring using Sentinel-1 data" (Ref: CGL2017-83704-P). This work has also been partially funded by the European Environment Agency through the project "Copernicus European Ground Motion Service - Supporting Services” (Project n 3436/RO-COPERNICUS/EEA.57704).

\section{REFERENCES}

Amelung, F., Galloway, D.L., Bell, J.W., Zebker, H.A., Laczniak, R.J., 1999. Sensing the ups and downs of Las Vegas: InSAR reveals structural control of land subsidence and aquifersystem deformation. Geology, 27(6), 483-486.

Antonielli, B., Monserrat, O., Bonini, M., Righini, G., Sani, F., Luzi, G., Feyzullayev, A.A., Aliyev, C.S., 2014. Pre-eruptive ground deformation of Azerbaijan mud volcanoes detected through satellite radar interferometry (DInSAR). Tectonophysics, 637, 163-177.

Barra, A., Monserrat, O., Mazzanti, P. Esposito, C., Crosetto, M., Scarascia Mugnozza, G., 2015. First insights on the potential of Sentinel- 1 for landslides detection. Geomatics Natural Hazards and Risks. 7(6), 1-10.

Béjar-Pizarro, M., Notti, D., Mateos, R.M., Ezquerro, P., Centolanza, G., Herrera, G., Bru, G., Sanabria, M., Solari, L., Duro, J. and Fernández, J., 2017. Mapping vulnerable urban areas affected by slow-moving landslides using Sentinel-1 InSAR data. Remote Sensing. 9(9), 876.

Carlà, T., Farina, P., Intrieri, E., Ketizmen, H., Casagli, N. 2018. Integration of ground-based radar and satellite InSAR data for the analysis of an unexpected slope failure in an openpit mine. Engineering Geology, 235, 39-52.

Comerci, V., Vittori, E., 2019. The Need for a Standardized Methodology for Quantitative Assessment of Natural and Anthropogenic Land Subsidence: The Agosta (Italy) Gas Field Case. Remote Sensing. 11(10), 1178.

Costantini, M., Ferretti, A., Minati, F., Falco, S., Trillo, F., Colombo, D., Novali, F., Malvarosa, F., Mammone, C., Vecchioli, F., Rucci, A., 2017. Analysis of surface deformations over the whole Italian territory by interferometric processing of ERS, Envisat and COSMO-SkyMed radar data. Remote Sensing of Environment, 202, 250-275. 
Crosetto, M., Monserrat, O., Iglesias, R., Crippa, B., 2010. Persistent Scatterer Interferometry: potential, limits and initial C- and X-band comparison. Photogrammetric Engineering \& Remote Sensing, 76(9), 1061-1069.

Crosetto, M., Monserrat, O., Cuevas-González, M. Devanthéry, N., Crippa, B., 2016. Persistent Scatterer Interferometry: a review. ISPRS Journal of Photogrammetry and Remote Sensing, $115,78-89$.

Del Soldato, M., Solari, L., Raspini, F., Bianchini, S., Ciampalini, A., Montalti, R., Ferretti, A., Pellegrineschi, V., Casagli, N., 2019. Monitoring Ground Instabilities Using SAR Satellite Data: A Practical Approach. ISPRS International Journal of Geo-Information. 8(7), 307.

De Luca, C., Zinno, I., Manunta, M., Lanari, R., Casu, F., 2017. Large areas surface deformation analysis through a cloud computing P-SBAS approach for massive processing of DInSAR time series. Remote Sensing of Environment. 202, 317.

Devanthéry, N., Crosetto, M., Monserrat, O., Crippa B., Mróz, M., 2018. Data analysis tools for persistent scatterer interferometry based on Sentinel-1 data, European Journal of Remote Sensing, 52(S1), 15-25.

Du, Z., Ge, L., Ng, A. H. M., Zhu, Q., Yang, X., Li, L., 2018. Correlating the subsidence pattern and land use in Bandung, Indonesia with both Sentinel-1/2 and ALOS-2 satellite images. International Journal of Applied Earth Observation and Geoinformation. 67, 54-68.

EGMS Task Force, 2017, https://land.copernicus.eu/usercorner/technical-library/egms-white-paper.

Ferretti, A., Prati, C., Rocca, F., 2000. Nonlinear subsidence rate estimation using permanent scatterers in differential SAR interferometry. IEEE TGRS. 38(5), 2202-2212.

Ferretti, A., Prati, C., Rocca, F., 2001. Permanent scatterers in SAR interferometry. IEEE TGRS. 39(1), 8-20.

Ferretti, A., Fumagalli, A., Novali, F., Prati, C., Rocca, F., Rucci, A., 2011. A new algorithm for processing interferometric data-stacks: SqueeSAR. IEEE TGRS, 49(9), 3460-3470.

García-Davalillo, J.C., Herrera, G., Notti, D., Strozzi, T., Álvarez-Fernández, I., 2014. DInSAR analysis of ALOS PALSAR images for the assessment of very slow landslides: the Tena Valley case study. Landslides, 11(2), 225-246.

Kalia, A.C., Frei, M. and Lege, T., 2017. A Copernicus downstream-service for the nationwide monitoring of surface displacements in Germany. Remote Sensing of Environment, 202, pp.234-249.

Hanssen, R., 2001. Radar interferometry. Kluwer Academic Publishers, Dordrecht (The Netherlands).

Intrieri, E., Raspini, F., Fumagalli, A., Lu, P., Del Conte, S., Farina, P., Allievi, J., Ferretti, A., Casagli, N., 2018. The Maoxian landslide as seen from space: detecting precursors of failure with Sentinel-1 data. Landslides. 15(1), 123-133.
Larsen et al., 2020. https://land.copernicus.eu/usercorner/technical-library/egms-specification-and-implementation -plan.

Massonnet, D., Feigl, K.L., 1998. Radar interferometry and its application to changes in the Earth's surface. Reviews of Geophysics. 36(4), 441-500.

Massonnet, D., Sigmundsson, F., 2000. Remote sensing of volcano deformation by radar interferometry from various satellites. In: Mouginis-Mark et al. (eds), Remote sensing of active volcanism. Geophysical monograph, 116, 207-221.

Ng, A. H. M., Ge, L., Du, Z., Wang, S., Ma, C., 2017. Satellite radar interferometry for monitoring subsidence induced by longwall mining activity using Radarsat-2, Sentinel-1 and ALOS-2 data. International Journal of Applied Earth Observation and Geoinformation. 61, 92-103.

Peltzer, G., Rosen, P., 1995. Surface displacement of the 17 May 1993 Eureka Valley, California, earthquake observed by SAR interferometry. Science, 268(5215), 1333-1336.

Pepe, A. and Calò, F., 2017. A review of interferometric synthetic aperture RADAR (InSAR) multi-track approaches for the retrieval of Earth's surface displacements. Applied Sciences, 7(12), p.1264.

Raspini, F., Bianchini, S., Ciampalini, A., Del Soldato, M., Solari, L., Novali, F., Del Conte, S., Rucci, A., Ferretti, A. and Casagli, N., 2018. Continuous, semi-automatic monitoring of ground deformation using Sentinel-1 satellites. Scientific reports, 8(1), 7253.

Rignot, E.J., Gogineni, S.P., Krabill, W.B., Ekholm, S., 1997. North and northeast Greenland ice discharge from satellite radar interferometry. Science, 276(5314), 934-937.

Solari, L., Del Soldato, M., Montalti, R., Bianchini, S., Raspini, F., Thuegaz, P., Bertolo, D., Tofani, V. and Casagli, N., 2019. A Sentinel-1 based hot-spot analysis: landslide mapping in northwestern Italy. International Journal of Remote Sensing. 40(20), 7898-7921.

Solari, L., Bianchini, S., Franceschini, R., Barra, A., Monserrat, O., Thuegaz, P., Bertolo, D., Crosetto, M. and Catani, F., 2020. Satellite interferometric data for landslide intensity evaluation in mountainous regions. International Journal of Applied Earth Observation and Geoinformation, 87, 102028.

Sowter, A., Amat, M. B. C., Cigna, F., Marsh, S., Athab, A., Alshammari, L., 2016. Mexico City land subsidence in 20142015 with Sentinel-1 IW TOPS: Results using the Intermittent SBAS (ISBAS) technique. International Journal of Applied Earth Observation and Geoinformation. 52, 230-242.

Torres, R., Snoeij, P., Geudtner, D., Bibby, D., Davidson, M., Attema, E., Potin, P., Rommen, B., Floury, N., Brown, M., Traver, I.N., 2012. GMES Sentinel-1 mission. Remote Sensing of Environment. 120, 9-24.

Zinno, I., Mossucca, L., Elefante, S., De Luca, C., Casola, V., Terzo, O., Casu, F., Lanari, R., 2015. Cloud computing for earth surface deformation analysis via spaceborne radar imaging: A case study. IEEE Transactions on Cloud Computing, 4(1), 104118. 